\title{
Autophagy Is a Component of Epithelial Cell Fate in Obstructive Uropathy
}

\author{
Ling Li, ${ }^{*}$ Diana Zepeda-Orozco, ${ }^{*}$ Rachel Black, ${ }^{\text {* }}$ \\ and Fangming Lin*† \\ From the Department of Pediatrics," and Division of Basic \\ Science, ${ }^{\dagger}$ University of Texas Southwestern Medical Center at \\ Dallas, Dallas, Texas
}

Epithelial cell fate and nephron loss in obstructive uropathy are not fully understood. We produced transgenic mice in which epithelial cells in the nephrons and collecting ducts were labeled with enhanced yellow fluorescent protein, and tracked the fate of these cells following unilateral ureteral obstruction (UUO). UUO led to a decrease in the number of enhanced yellow fluorescent protein-expressing cells and down-regulation of epithelial markers, Ecadherin, and hepatocyte nuclear factor-1 $\beta$. Following UUO, enhanced yellow fluorescent protein-positive cells were confined within the tubular basement membrane, were not found in the renal interstitium, and did not express $\alpha$-smooth muscle actin or S100A4, markers of myofibroblasts and fibroblasts. Moreover, when proximal tubules were labeled with dextran before UUO, dextran-retaining cells did not migrate into the interstitium or express $\alpha$-smooth muscle actin. These results indicate that UUO leads to tubular epithelial loss but does not cause epithelial-tomesenchymal transition that has been shown by others to be responsible for nephron loss and interstitial fibrosis. For the first time, we found evidence of enhanced autophagy in obstructed tubules, including accumulation of autophagosomes, increased expression of Beclin 1 , and increased conversion of microtubular-associated protein 1 light chain 3-I to -II. Increased autophagy may represent a mechanism of tubular survival or may contribute to excessive cell death and tubular atrophy after obstructive injury. (Am J Pathol 2010, 176:1767-1778; DOI: 10.2353/ajpath.2010.090345)

Obstructive uropathy and renal cystic dysplasia are the most common causes of end-stage renal disease in children. These disorders account for $16 \%$ of pediatric kidney transplantations in North America. ${ }^{1}$ The pathogenesis of these diseases is not fully understood. Obstruction of the kidney during fetal development results in renal cystic dysplasia, which is likely due to a disturbance in epithelial differentiation and maturation. ${ }^{2-5}$ In contrast, urinary tract obstruction in the postnatal kidney results in inflammation, tubular dilation, tubular atrophy, extracellular matrix accumulation, and renal fibrosis. ${ }^{6}$ Although the pathogenesis of obstructive uropathy is not identical in developing and mature kidneys, loss of normal renal tissue and increased interstitial fibrosis are common to both conditions.

The mechanism of tubular atrophy and nephron loss in obstructive uropathy has not been fully elucidated. Previous studies have shown that epithelial cell apoptosis plays an important role. 2,7 Epithelial-mesenchymal transition (EMT) has also been proposed as a mechanism of interstitial fibrosis as well as nephron loss. ${ }^{8,9}$ Lineage tracing studies in which proximal tubular cells were labeled with lacZ have shown that up to $36 \%$ of interstitial fibroblasts originate by EMT after unilateral ureteral obstruction (UUO). ${ }^{10}$ However, the extent to which EMT contributes to nephron loss and interstitial fibrosis remains controversial. ${ }^{10-12}$ In a rat model of angiotensin II-induced renal fibrosis, fibroblasts originate from encroachment of interstitial myofibroblasts from the perivascular space rather than via EMT. ${ }^{11}$ To further evaluate the role of EMT in nephron loss in obstructive uropathy, we performed lineage analysis using genetically modified mice in which epithelial cells of the proximal and distal nephron were labeled and cell fate was followed.

Autophagy is another potential mechanism of nephron loss in obstructive uropathy. Autophagy is a lysosomal degradation pathway that is essential for cell survival, embryonic development, and tissue homeostasis. ${ }^{13,14}$ Autophagy results in the degradation of cytoplasm by lysosomes in response to stress conditions, such as nu-

Supported in part by UT Southwestern O'Brien Kidney Research Center (NIDDK, DK079328), and funding from the Department of Pediatrics at UT Southwestern Medical Center at Dallas.

L.L. and D.Z.-O. contributed equally to this work.

Accepted for publication December 10, 2009.

Address reprint requests to Ling Li, M.D., Ph.D., Division of Pediatric Nephrology, MC 9063, Department of Pediatrics, University of Texas Southwestern Medical Center at Dallas, 5232 Harry Hines Boulevard, Dallas, TX 75390-9063. E-mail: linda.li@utsouthwestern.edu. 
trient deprivation. The morphological hallmark of autophagy is the autophagosome, which is a double-membrane-bound vacuole that contains cytoplasmic contents and organelles. Fusion of autophagosomes with lysosomes results in the formation of autophagolysosomes in which the captured material is degraded. Autophagy protects cells against diverse pathologies, including infection, cancer, neurodegeneration, aging, and other diseases. However, under certain conditions, this self-cannibalistic function may be detrimental and could be associated with excessive cell death. Emerging evidence indicates that apoptosis (type I programmed cell death) and autophagy (type II programmed cell death) are coordinated processes. Bcl-2 family members have been shown to be dual regulators of apoptosis and autophagy. ${ }^{15}$ Increased cell death due to apoptosis has been observed in obstructive uropathy. Here, we explored the possibility that autophagy may also contribute to excessive cell death associated with nephron loss and tubular atrophy.

\section{Materials and Methods}

\section{Unilateral Ureteral Obstruction}

Cre $^{k s p}$ mice $^{16,17}$ (gift from Dr. Peter Igarashi, University of Texas Southwestern Medical Center) were crossed with R26R-EYFP reporter mice ${ }^{18}$ (gift from Dr. Frank Costantini, Columbia University). The bitransgenic progeny $\left(C r e^{k s p} ; R 26 R-E Y F P\right)$ expressed EYFP specifically in epithelial cells of the renal tubules and ureters. Mice (6 to 12 weeks old) were anesthetized with isoflurane, and the left ureter was exposed via a mid-abdominal incision. The mid-ureter was obstructed by two point ligations with silk sutures. Sham-operated mice underwent the same procedure except for the obstruction of the left ureter. The abdominal incision was closed and mice were allowed to recover. Mice were sacrificed 3 to 14 days after surgery. The kidneys were perfused in situ with PBS followed by $4 \%$ paraformaldehyde administered via the left ventricle before harvesting. Kidneys were further fixed with $4 \%$ paraformaldehyde before embedding in paraffin or optimal cutting temperature medium. Paraffin sections (5 $\mu \mathrm{m}$ thick) were stained with Gomori's trichrome or periodic acid-Schiff stains. Kidney cryosections ( $5 \mu \mathrm{m}$ thick) were used for immunostaining. All experiments were performed with the approval of the Institutional Animal Care and Research Advisory Committee at the University of Texas Southwestern Medical Center at Dallas.

\section{Immunostaining and Image Analysis}

Immunostaining of kidneys was performed using established methods. ${ }^{19}$ The primary antibodies were directed against enhanced green fluorescent protein (EGFP) that cross reacted with EYFP (1:200; Rockland Immunochemicals, Inc., Gilbertsville, PA), entactin (1:1000; Chemicon International Inc., Temecula, CA), E-cadherin (1:200; Zymed Laboratories, Invitrogen Corporation, Carlsbad, CA), hepatocyte nuclear factor (HNF-1 $\beta$; 1:200; Santa
Cruz Biotechnology Inc. Santa Cruz, CA), $\alpha$ smooth muscle actin ( $\alpha$-SMA; Cy3- or fluorescein isothiocyanate-labeled; 1:200; Sigma, Saint Louis, MO), S100A4 (1:200; Covance, Berkeley, CA), CD45 (1:500, InvitrogenCaltag), CD31 (1:50; BD Biosciences Pharmingen, San Jose, CA), and lysosomal-associated membrane protein-1 (LAMP-1; 1:2000, Abcam Inc., Cambridge, MA). Proximal tubules were stained with fluorescein isothiocyanate-conjugated Lotus tetragonolobus agglutinin (LTA, 1:50, Vector Laboratories, Burlingame, CA). Thick ascending limbs were stained with an antibody against $\mathrm{Na}-\mathrm{K}-\mathrm{Cl}$ co-transporter (1:200; $\alpha$ Diagnostic International, San Antonio, TX). Distal tubules and connecting tubules were stained with an antibody against NCX1 (1:2000; gift from Dr. Kenneth Phillipson, David Geffen School of Medicine at UCLA, Los Angeles, CA). Collecting ducts were stained with an antibody against AQP3 (1:500, Chemicon,Millipore, Billerica, MA). Secondary antibodies included Alexa Fluor 488-conjugated goat anti-mouse IgG, Alexa Fluor 594-conjugated goat anti-rabbit IgG, and Alexa Fluor 488-conjugated goat anti-rat IgG (1:400, Molecular Probes, Eugene, OR). Tissue sections were incubated with the primary antibodies at $4^{\circ} \mathrm{C}$ overnight or at room temperature for 2 hours after permeabilization with $0.1 \%$ Triton X100 in PBS and blocking with $10 \%$ goat serum and $0.5 \%$ bovine serum albumin. The sections were washed then incubated with the appropriate secondary antibodies for 1 hour at room temperature. Sections were visualized with a Zeiss Axioplan 2 microscope and photographed with a digital camera, and the images were analyzed with Axiovision software (Carl Zeiss International, Oberkochen, Germany). Some images were acquired using a Zeiss LSM 510 Meta confocal laser scanning microscope (Carl Zeiss International, Oberkochen, Germany).

\section{Evaluation of Tubular Atrophy and Tubular Cell Apoptosis}

Tubular atrophy was measured using semiquantitative morphological analysis as described. ${ }^{20,21}$ Briefly, kidney sections from three mice at each time point were stained with periodic acid-Schiff, and images of random fields were acquired at $\times 200$ magnification. In each sample, at least 1000 proximal tubules were identified and scored. Renal tubules with the following histological changes were considered atrophic: tubules with a thickened and wrinkled basement membrane and simplified epithelium; round tubules with simplified epithelium and casts; or small tubules with narrow lumens, clear cells and relatively thin basement membranes. Samples were classified based on the percentage of atrophic tubules: no atrophy $(0 \%)$, mild focal atrophy ( $1 \%$ to $15 \%)$, moderate atrophy ( $16 \%$ to $30 \%$ ), and extensive atrophy ( $\geq 31 \%$ ).

To measure apoptosis, terminal deoxynucleotidyl transferase dUTP nick-end labeling staining was performed on paraffin sections according to the manufacturer's directions (In Situ Cell Death Detection Kit TMR Red, Roche Applied Science, Indianapolis, IN). Proximal tubules in the cortex were labeled with fluorescein isothiocyanate-conjugated LTA (1:50, Vector Laboratories) and random fields were 
photographed at $\times 400$ magnification to obtain $10 \mathrm{im}$ ages. The percentage of apoptotic cells in the proximal tubules was calculated.

\section{Transmission Electron Microscopy}

Mice were sacrificed at 7 and 14 days after UUO or sham-operation. The kidneys were perfused with PBS and fixed by immersion in $0.1 \mathrm{~mol} / \mathrm{L}$ cacodylate buffer containing $2.5 \%$ glutaraldehyde. Samples were dehydrated, embedded, sectioned (90 nm thick) and stained with lead citrate and $2 \%$ aqueous uranyl acetate. Duplicate samples were examined using a Tecnai G2 Spirit $120 \mathrm{KV}$ transmission electron microscope (FEl Company, Hillsboro, OR) available in the Electron Microscopy Core at UT Southwestern Medical Center. Proximal tubules were identified by the presence of a brush border and abundant mitochondria. About 40 proximal tubules in each sample were photographed with a SIS Morada 11 mpixel side mount CCD camera and examined for autophagic vacuoles.

\section{Real-Time Reverse Transcription-PCR and Immunoblot Analyses}

Real-time reverse transcription (RT)-PCR was performed with SYBR Green Supermix (Bio-Rad Laboratories Inc., Hercules, CA) using an iCycler iQ machine (Bio-Rad Laboratories Inc., Hercules, CA) as described. ${ }^{22}$ Standard curves were produced to demonstrate linearity and determine efficiency. The expression of Beclin 1 relative to $18 \mathrm{~S}$ rRNA was calculated using the method of Pfaffl. ${ }^{23}$ Kidney extracts were prepared, and immunoblot analysis was performed as described previously. ${ }^{22}$ Immunoblots were probed with antibodies against LC3 (Novus Biologicals Inc., Littleton, CO), Beclin 1 (1:500, Santa Cruz Biotechnology Inc.), LAMP-1 (1:2000, Abcam Inc. Cambridge, MA), and cathepsin D (1:500, Santa Cruz Biotechnology Inc.) followed by detection with chemiluminescence. Anti- $\alpha$-tubulin antibody (1:5000, Sigma-Al- drich) was used as a loading control. Band intensities were quantified using FluorChem 8900 analysis software ( $\alpha$ Innotech Corporation, San Leandro, CA).

\section{In Vivo Labeling of Proximal Tubular Cells with Fluorescent Dextran}

Proximal tubules can be labeled with a low molecular weight dextran by endocytotic uptake. ${ }^{11,24}$ Male C57BL/6 mice ( 6 weeks old) were injected via tail vein with $0.2 \mathrm{mg}$ Texas Red-dextran (3000 MW, Invitrogen) in $0.2 \mathrm{ml} \mathrm{PBS.}$ UUO or sham-operation was performed 48 hours later, and kidneys were harvested 3 to 14 days after surgery. Three to five mice were used at each time point. Kidney frozen sections were stained with antibodies against entactin and $\alpha$-SMA. Proximal tubules were identified by labeling with fluorescein isothiocyanate-LTA, and the percentage of dextran-retaining cells was calculated. At least 10 images acquired at $\times 400$ magnification were used for quantification of each sample.

\section{Statistical Analysis}

Data shown are mean $\pm \mathrm{SE}$. The number of animals used is indicated in each experiment. The significance of the differences between the means was calculated using Student's $t$-test. Analysis of variance was used for multiple comparisons. $P<0.05$ was considered statistically significant.

\section{Results \\ UUO Leads to the Loss of a Mature Epithelial Phenotype}

Previous studies have shown that complete urinary tract obstruction in the mature kidney causes epithelial injury, tubular dilation, and inflammation. ${ }^{25}$ We performed UUO in mice and observed significant tubular dilation in all nephron segments and collecting ducts in the obstructed kidney

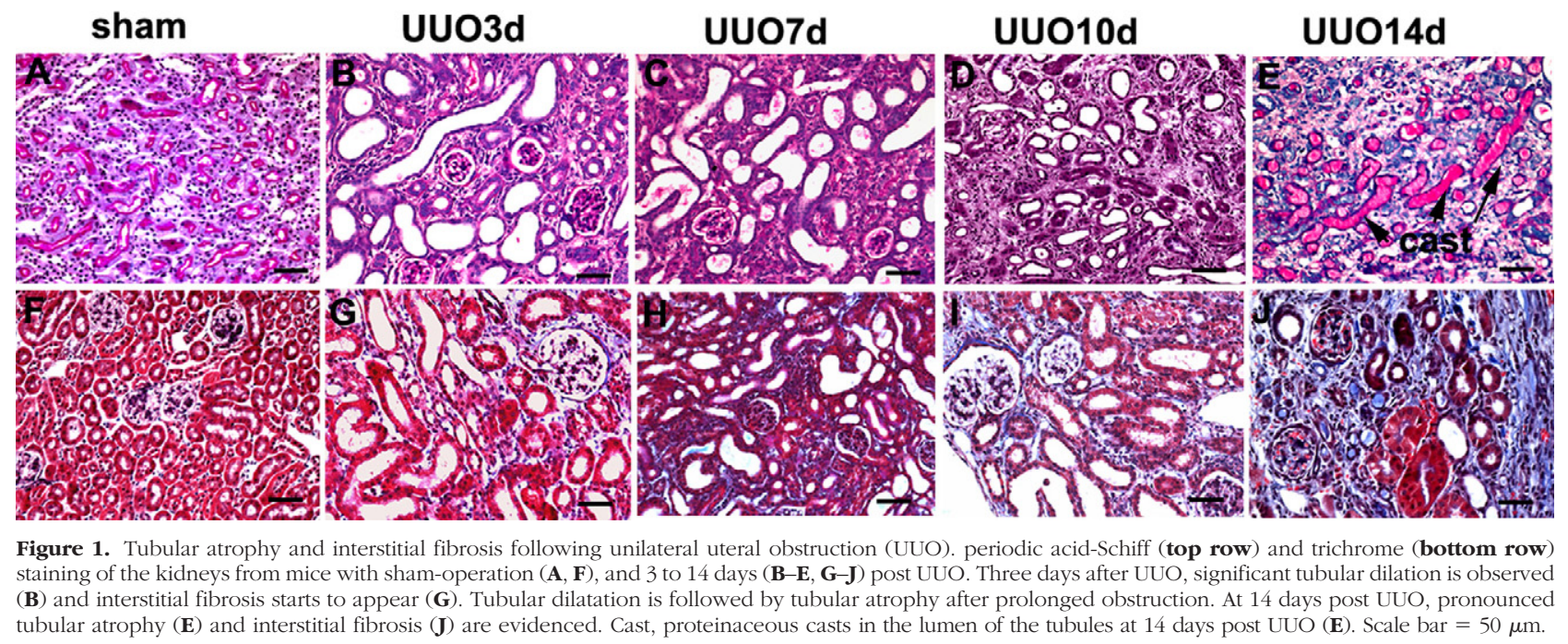


A Co

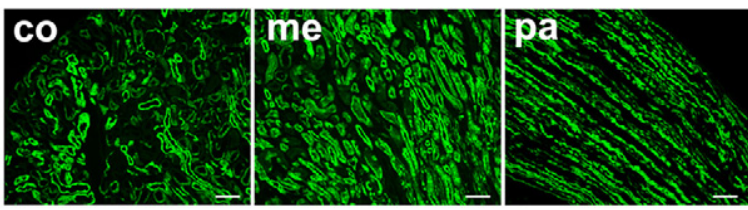

B

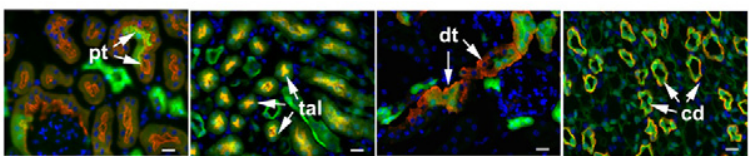

Figure 2. Renal tubular expression of EYFP in control Cre $e^{k s p} ; R 26 R-E Y F P$ mice. A: Low power views of EYFP expression (green) in renal cortex (co), medulla (me) and papilla (pa). Scale bar $=50 \mu \mathrm{m}$. B: EYFP (green) is expressed in proximal tubules (pt) stained with LTA (red), and other nephron segments with antibodies to $\mathrm{Na}-\mathrm{K}-\mathrm{Cl}$ co-transporter (red) for thick ascending limbs (tal), NCX1 (red) to distal tubules and connecting tubules (dt), and $\mathrm{AQP} 3$ (red) to collecting ducts (cd). Scale bar $=20 \mu \mathrm{m}$.

(Figure 1, A-J). All tubules were dilated 7 days after UUO. Tubule dilation was maximal at 10 days after which tubular atrophy became more predominant. Proximal tubular injury was evidenced by the loss of brush border 3 days after UUO. Two weeks after UUO, atrophic tubules were filled with proteinaceous casts. Trichrome staining showed matrix accumulation and interstitial fibrosis (Figure 1).

To examine the fate of tubular epithelial cells after ureteral obstruction, we used a genetic approach to label cells in the nephrons and collecting ducts with EYFP. $\mathrm{Cre}^{k s p}$ transgenic mice express Cre recombinase under the direction of the Ksp-cadherin (Ksp) promoter in tubular epithelial cells of all segments of the nephron and collecting ducts and in developing uroepithelial cells. Cre is not expressed in blood vessels, glomerular cells, or interstitial cells. ${ }^{16,17}$ Furthermore, Cre is not expressed in extra-renal tissues including bone marrow cells. ${ }^{19} \mathrm{Cre} \mathrm{ksp}^{\mathrm{ksp}}$ mice were crossed with R26R-EYFP reporter mice, ${ }^{18}$ which carry an EYFP reporter gene that is activated only in the presence of Cre recombinase. ${ }^{19}$ Once the EYFP gene is activated, it is expressed under the control of the ubiquitous Rosa26 promoter. Consequently, EYFP will continue to be expressed in the labeled cells and all their progeny, irrespective of whether they continue to express Cre. Bitransgenic Cre ${ }^{k s p} ; R 26 R-E Y F P$ mice expressed EYFP specifically in the epithelial cells of all nephron segments and collecting ducts (Figure 2, A-B). In shamoperated mice, EYFP was expressed in $21 \%$ of proximal tubular cells, $99 \%$ of thick ascending limb cells, $92 \%$ of distal tubular and connecting tubular cells, and $100 \%$ of collecting duct cells. The high degree of tubular epithelial labeling in the distal nephron and collecting ducts allowed reliable tracing of cell fate in these segments following urinary tract obstruction.

The increased hydrostatic pressure and mechanical strain produced by UUO can cause tubular epithelial injury and death. ${ }^{26,27}$ In Cre ${ }^{k s p}$;R26R-EYFP mice, ureteral obstruction led to the gradual atrophy of tubules and decreased number of EYFP-expressing cells (Figure 3A, upper panel). The kidneys were further examined for the expression of epithelial markers E-cadherin (Figure 3A, lower panel) and HNF-1 $\beta$ (Figure 3B). E-cadherin, which is normally expressed in the basolateral membrane of tubular cells, was down-regulated in atrophic tubules. Similarly, HNF-1 $\beta$, which is expressed in differentiated epithelia in the kidney and other organs, ${ }^{28,29}$ was detected in the nuclei of all tubular epithelial cells in shamoperated kidneys. However, the number of cells expressing HNF-1 $\beta$ decreased in the dilated and atrophic tubules beginning 7 to 10 days after obstruction. Few cells expressed HNF-1 $\beta 14$ days after UUO. These results indicated that tubular epithelial cells lose their mature epithelial phenotype after obstructive injury.
A

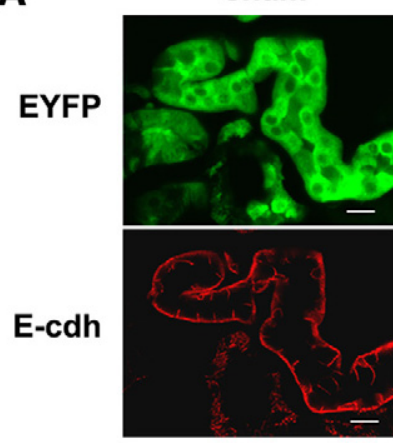

B

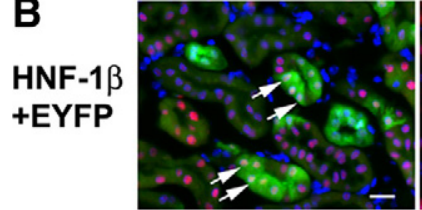

UUO 3d
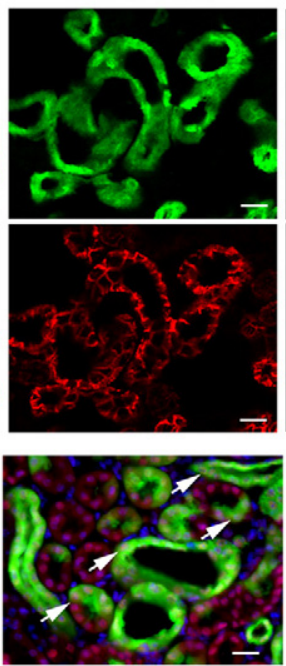

UUO 7d
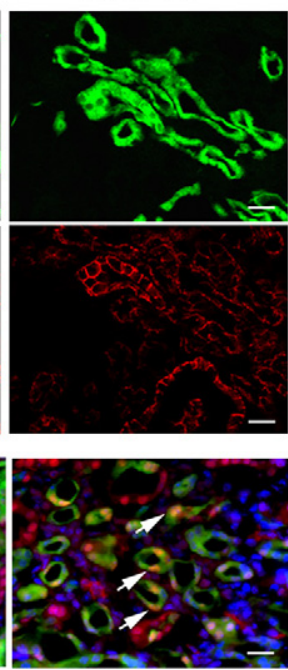

UUO 10d
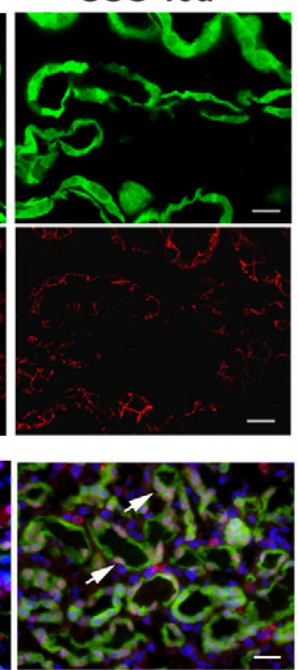

UUO 14d
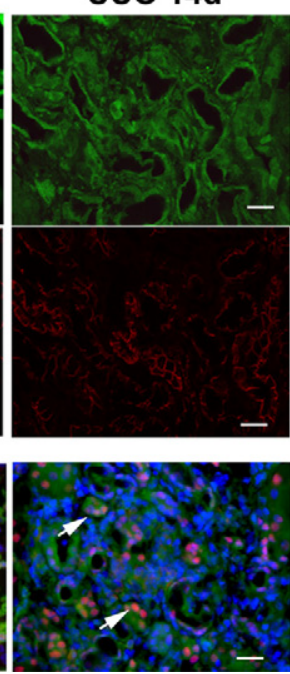

Figure 3. Loss of mature tubular epithelial cell expression pattern after prolonged UUO. A: Decreased expression of EYFP and E-cadherin. Normal renal tubular epithelial cells in $C r e^{k s p} ; R 26 R-E Y F P$ mice express EYFP in the cytoplasm (green) and E-cadherin at the basolateral aspect (red). With ureteral obstruction, tubular atrophy occurs as indicated by the decrease in EYFP-expressing cells. E-cadherin expression is down-regulated in the corresponding tubules. E-cdh, E-cadherin. B: Decreased expression of epithelial marker HNF-1 $\beta$. HNF- $1 \beta$ expression (red) is decreased in EYFP-expressing epithelial cells (green) following UUO. Arrows indicate the nuclear expression of HNF-1 $\beta$. Nuclei are counterstained with DAPI (blue). Scale bar $=20 \mu \mathrm{m}$. 

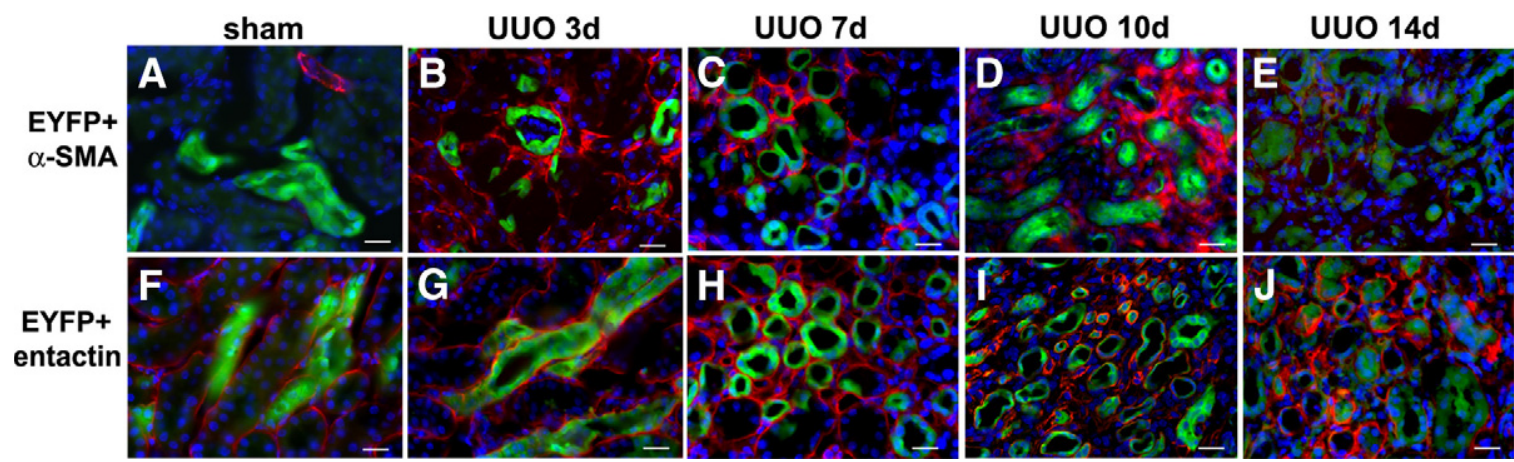

Figure 4. Tubular epithelial cells do not migrate outside the tubular basement and become myofibroblasts during interstitial fibrosis in $C r e^{k s p} ; R 26 R-E Y F P$ mice. A-E: Immunostaining of $\alpha$-SMA (red) and EYFP (green) in the kidneys of the control (A), and 3 to 14 days after UUO (B-E) shows the absence of $\alpha$-SMA expression in EYFP-positive tubular cells. There are abundant $\alpha$-SMA-expressing cells in the interstitium. F-J: EYFP (green) and tubular basement membrane marker entactin (red) staining shows that all EYFP-positive cells are confined within the tubular basement membrane in the kidneys of the control (F) and 3 to 14 days after UUO $(\mathbf{G}-\mathbf{J})$. Nuclei are counterstained with DAPI (blue). Scale bar $=20 \mu \mathrm{m}$.

\section{EYFP-Expressing Tubular Epithelial Cells Do Not Become Interstitial Myofibroblasts}

Because EMT has been shown to occur in epithelial cells in cultures $^{9}$ and in the obstructed mouse kidney, ${ }^{10}$ we examined whether EMT could account for nephron loss and interstitial fibrosis following UUO. In $\mathrm{Cre}^{k s p} ; \mathrm{R} 26 \mathrm{R}$ EYFP mice, tubular epithelial cells are permanently marked with EYFP, which allows us to track epithelial cell fate after UUO. Kidneys were harvested 3 days after UUO, when fibrosis began, to 14 days after UUO, when extensive fibrosis was established. To determine whether tubular epithelial cells adopted a myofibroblast cell fate, kidney sections were co-stained with antibodies against EYFP and $\alpha$-SMA. Although an increased number of $\alpha$-SMA-expressing cells was detected in the interstitium of the obstructed kidneys, no $\alpha$-SMA expression was observed in EYFP-positive cells (Figure 4, A-E). All $\mathrm{EYFP}^{+}$cells were confined within the tubular basement membrane, which was stained with an antibody against entactin (Figure 4, F-J). These results indicated that mature tubular epithelial cells did not convert to $\alpha$-SMAexpressing interstitial myofibroblasts during the course of renal fibrosis following UUO.

Next, kidney sections were stained with an antibody to S100A4, a cytoplasmic calcium binding protein also known as fibroblast-specific protein 1 (FSP1). Expression of S100A4 has been shown to increase in renal fibrosis due to anti-tubular basement membrane disease or UUO ${ }^{10,30}$ We found that S100A4 was not expressed in EYFP-positive epithelial cells in sham-operated kidneys (Figure 5A). S100A4 was expressed in a few cells located in the renal interstitium. The interstitial S100A4expressing cells co-expressed markers of endothelial cells (CD31) or leukocytes (CD45) (not shown). These results are consistent with previous findings that S100A4 is expressed in endothelial cells and white blood cells, including macrophages, granulocytes, and lymphocytes. ${ }^{12,31-33}$ To examine the expression of S100A4 in the obstructed kidney, we sacrificed mice $3,7,10$, and 14 days after $\mathrm{U} \cup \mathrm{O}(n=3)$ and stained the kidney sections with an antibody against S100A4. Scanning of entire sections revealed no expression of S100A4 in EYFP- positive cells. A large number of S100A4-expressing cells was detected in the interstitium (Figure 5A). Most S100A4-expressing interstitial cells were localized to peritubular areas (Figure 5B, top panel) and co-expressed the leukocyte marker CD45, indicating that they represented infiltrating inflammatory cells (Figure 5B, middle panel). A few S100A4-expressing cells in the interstitium co-expressed CD31 (Figure 5B, bottom panel). These results indicate that tubular epithelial cells in the distal nephron and collecting ducts do not convert into S100A4-expressing fibroblasts following urinary tract obstruction.

\section{Dextran-Retaining Proximal Tubular Cells Do Not Migrate Outside the Basement Membrane and Express $\alpha$-SMA}

In Cre ${ }^{k s p} ;$ R26R-EYFP mice, only $21 \%$ of the proximal tubular cells were labeled with EYFP, which limited its utility for lineage tracing in this nephron segment. To specifically address whether proximal tubular cells of the adult kidney can be converted into myofibroblasts in response to obstructive injury, we labeled proximal tubules of wildtype mice with Texas-Red-conjugated low molecular dextran. ${ }^{11}$ More than $89 \%$ to $98 \%$ of the proximal tubules retained dextran 3 to 14 days after UUO or sham-operation ( $n=3$ to 5). Although red fluorescent signals were weaker in some cells after UUO, no significant difference in the percentage of dextran-retaining cells was observed between the UUO group or the control group at any time point (Figure 6, A-B). These results confirm the usefulness of dextran labeling of proximal tubules. ${ }^{11}$ Examination of the obstructed kidneys showed that no dextran-retaining cells migrated outside the tubular basement membrane or expressed $\alpha$-SMA in the interstitium (Figure $6 \mathrm{C}$ ). These results provide a second line of evidence indicating that tubular epithelial cells do not migrate into the interstitium to form myofibroblasts following UUO. Hence, EMT does not play a substantial role in nephron loss in the obstructed kidney. 
A

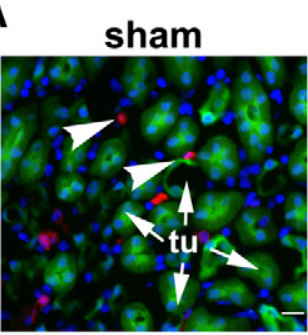

UUO 3d

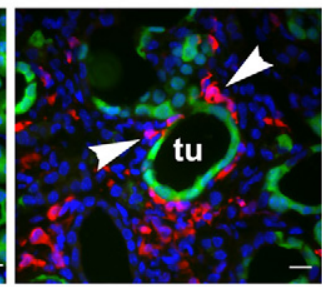

B

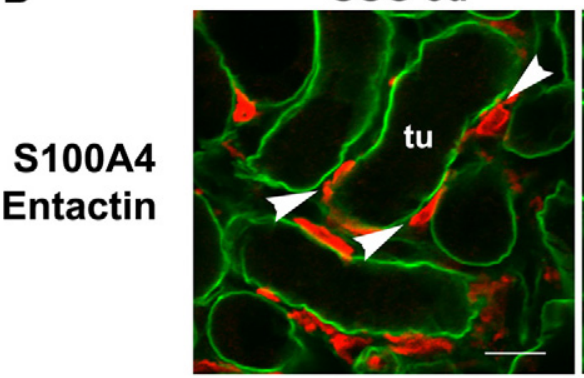

UUO 3d

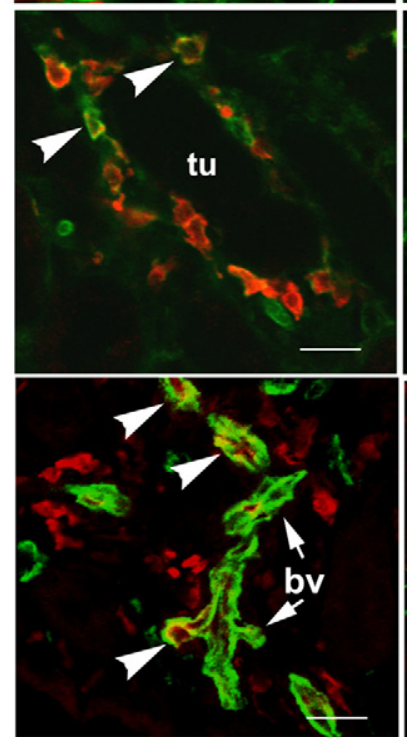

UUO 7d

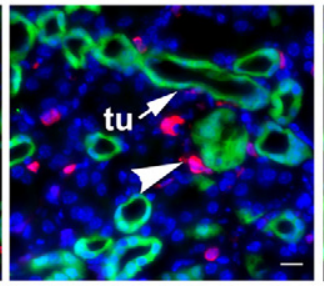

UUO 10d
UUO 10d

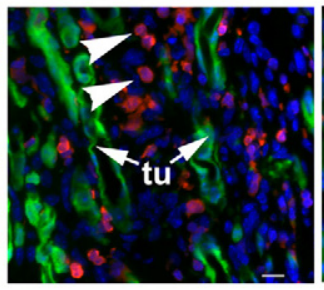

UUO 14d

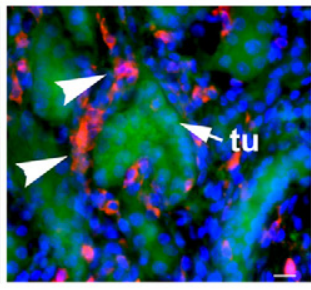

Figure 5. EYFP-positive tubular cells do not express S100A4 in $C r e^{k s p} ; R 26 R-E Y F P$ mice. A: No expression of S100A4 (red, arrowheads) was detected in EYFP-positive tubular cells (green) in control and 3 to 14 days after UUO. Nuclei are counterstained with DAPI (blue). B: All S100A4 expressing cells (red, arrowheads) are localized to the interstitium and outside the dilated tubules stained with the tubular basement membrane marker entactin (green). Some S100A4-expressing cells (red) in the peritubular areas co-express leukocyte maker CD 45 (green, arrowheads), and some S100A4-expressing cells (red) co-express endothelial maker CD31 (green, arrowheads) in the blood vessels (bv). tu, tubules. Scale bar $=20 \mu \mathrm{m}$.

\section{Increased Autophagy in Obstructed Renal Tubules}

Next, we investigated the contribution of cell death to nephron loss. It is well known that apoptosis is increased in obstructed renal tubules. ${ }^{2,7}$ In contrast, the significance of autophagy, or type II programmed cell death, in obstructive uropathy has not been demonstrated. Autophagy occurs in response to stress conditions, such as energy deprivation, hypoxia, mitochondrial dysfunction, and infection. It is usually regarded as a self-protective mechanism to recycle free amino acids and fatty acids, remove damaged organelles, and prevent protein aggregation. However, excessive autophagy can lead to destruction of essential proteins and organelles beyond a certain threshold causing cellular catastrophe. ${ }^{34} \mathrm{Be}-$ cause UUO produces ischemic and hypoxic stress to tubular cells, ${ }^{26,35-37}$ we reasoned that autophagy may play a role in nephron loss in kidneys with obstructive injury. Therefore, we examined the kidneys for morphological and biochemical evidence of autophagy.

The presence of autophagosomes, the double-membraned vacuoles containing degenerating cytoplasmic organelles and cytosol, is considered the gold standard for autophagy. ${ }^{38}$ During the formation of autophagosomes, specialized vacuoles arise from ER membranes and engulf targets of degradation. An autophagosome fuses with a lysosome to form an autophagolysosome to degrade its content. Using transmission electron microscopy, we examined renal tubules for cells containing autophagic vacuoles including autophagosomes and autophagolysosomes. As shown in Figure 7A, cells in control kidneys contained intact nuclei and normal mitochondria and other intracellular organelles. Rare autophagic vacuoles were detected in normal tubular cells. However, complete urinary tract obstruction led to an increased level of autophagy. Double membrane vacuoles that contained electron-dense material and compressed mitochondria with 
A

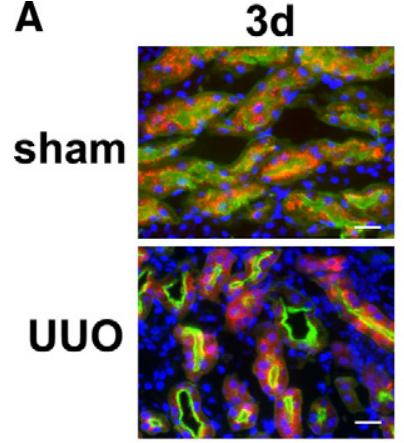

7d
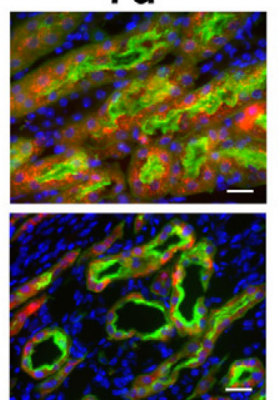

$10 d$
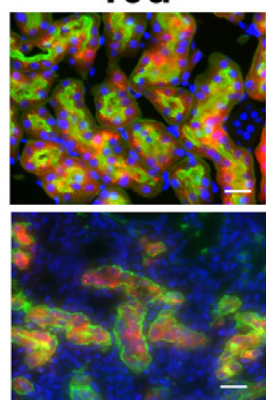

$14 d$
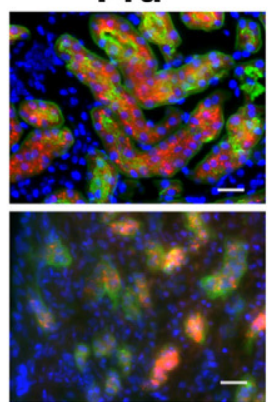

B

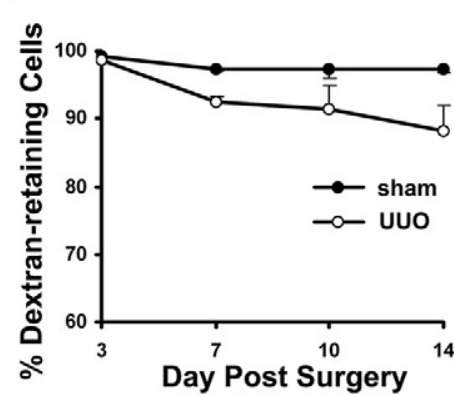

C

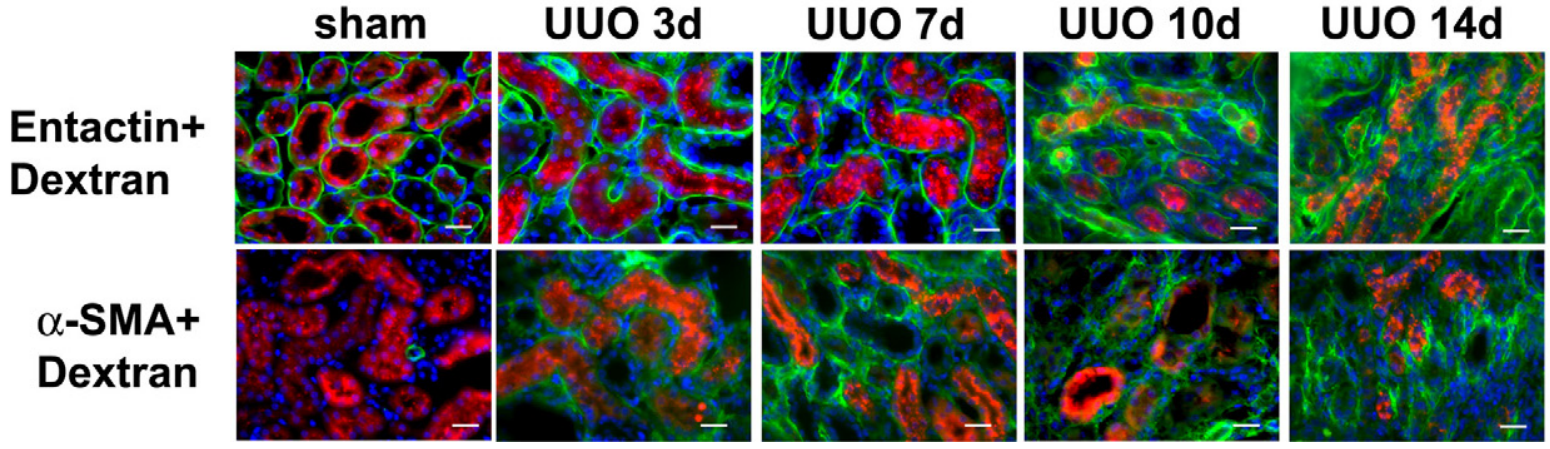

Figure 6. Dextran-retaining cells are confined to the proximal tubules and do not express $\alpha$-SMA in C57BL/6 mice. A: Proximal tubules identified by their binding with LTA (green) are labeled with a Texas-red conjugated small molecular weight dextran (red) in mice with sham-operation or UUO for 3 to 14 days. B: $89 \%$ to $98 \%$ of the proximal tubular cells retain dextran in the control and UUO groups. No statistically significant difference in dextran-retaining cells is detected between the control and UUO groups. Values represent mean \pm SE. $n=3$ to 5. C: Dextran-retaining cells (red) are confined inside the tubular basement membrane stained with entactin (green, top panel) and do not express myofibroblast marker a-SMA (green, bottom panel) in control and 3 to 14 days after UUO. Nuclei are counterstained with DAPI (blue). Scale bar $=20 \mu \mathrm{m}$.

loss of visible cristae were frequently observed in the tubules 7 and 14 days after UUO. Furthermore, most cells contained more than one autophagic vacuole. The autophagic cells showed no signs of apoptosis such as nuclear membrane breakdown, chromatin condensation, or plasma membrane blebbing. Aside from engulfed mitochondria inside autophagic vacuoles, mitochondrial changes not typically associated with autophagy, such as heterogeneously distributed internal cristae and matrix, were also observed (Figure 7A upper panel). An increased level of autophagy after UUO was accompanied by tubular atrophy (Figure 7A lower panel).

\section{Autophagy-Related Proteins are Up-Regulated in the Obstructed Kidneys}

In mammals, 11 autophagy-related genes (ATG) have been identified to date. Beclin 1 (BECN1, Vps30, or Atg6) is a key component of the autophagy stimulatory complex. Beclin 1 is involved in the initiation of autophagosome formation by forming a multiprotein complex. ${ }^{39-42}$ Beclin $1^{-1-}$ mice are embryonic lethal, ${ }^{43}$ indicating its importance in development. Beclin $1^{+/-}$mice are viable but have increased tumor formation. ${ }^{44}$ Cardiomyocytes of Beclin $1^{+/-}$mice exhibit decreased autophagy in response to pressure overload. ${ }^{45}$ We measured the mRNA levels of Beclin 1 in the kidneys with obstructive injury and found that Beclin 1 mRNA levels increased significantly 7 days and 14 days after UUO (Figure 7B). The increased expression of Beclin 1 protein was confirmed by immunoblot analysis. The abundance of Beclin 1 protein was significantly increased 7 days but not 14 days after UUO (Figure $7 \mathrm{C}$ ). The decline in the protein level at 14 days could be due to cellular changes associated with more advanced tubular atrophy, although we could not exclude the possibility of a difference in sensitivity between real time RT-PCR and immunoblot analyses.

Next, we examined the expression of autophagyrelated protein, Atg8/LC3, which is the only Atg protein that is known to be associated with completed autophagosome formation. Microtubule-associated protein 1 light-chain 3 (LC3) is cleaved to LC3-I immediately after its synthesis. The cytosolic LC3-I is then recruited to the membrane and converted to LC3-II after conjugation with phosphatidylethanolamine during the formation of the autophagosome. An increased conversion of LC3-I to LC3-II provides biochemical evidence of autophagy in mammalian cells. ${ }^{38}$ We measured LC3-I and LC3-II at 7 and 14 days following UUO. At both time points, the levels of LC3-I were decreased and the levels of LC3-II were increased (Figure 7D). The enhanced conversion of LC3-I to LC3-II indicated an increased level of autophagy.

The increased levels of LC3-II together with the electron microscopy findings indicate that autophagosomes accumulate following UUO. To exclude the possibility that the increased abundance of autophagosomes was due to lysosomal dysfunction preventing autophagosome clearance, we examined the expression of lysosomal proteins, LAMP-1 and lysosomal enzyme cathepsin D. 
A

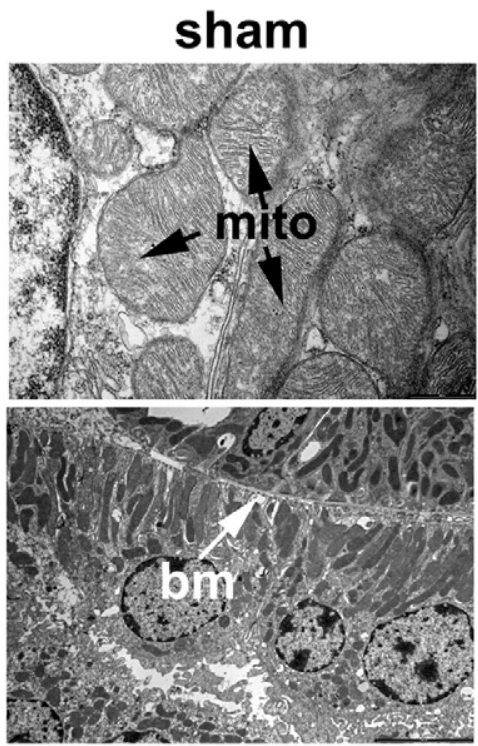

B
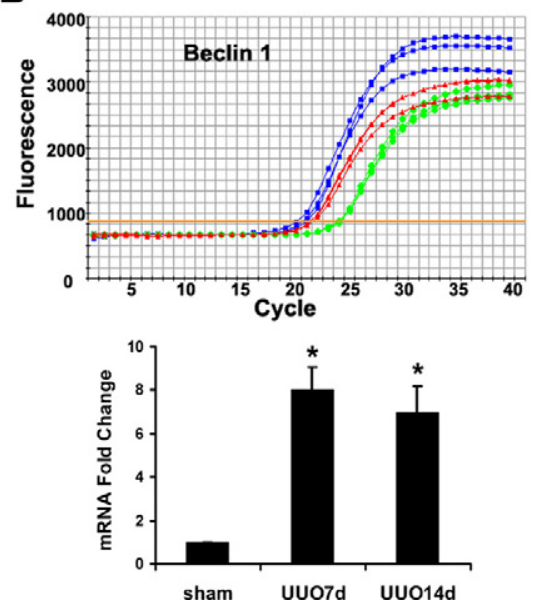

UUO 7d

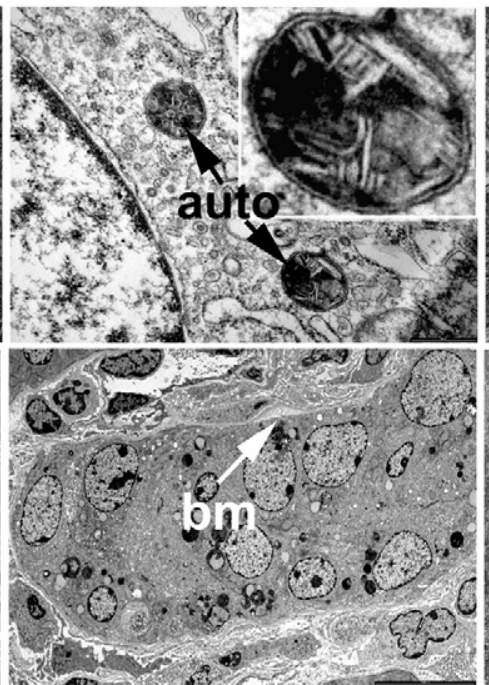

C
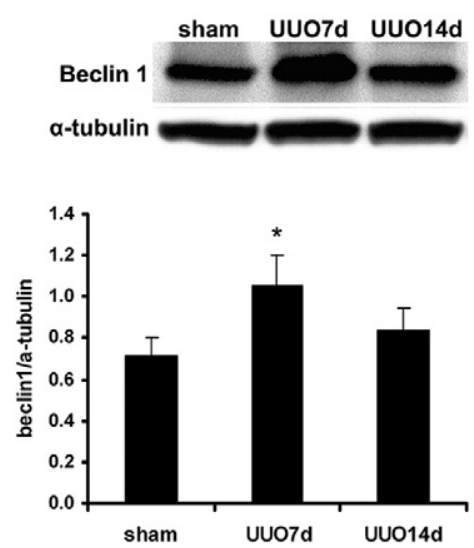

UUO 14d

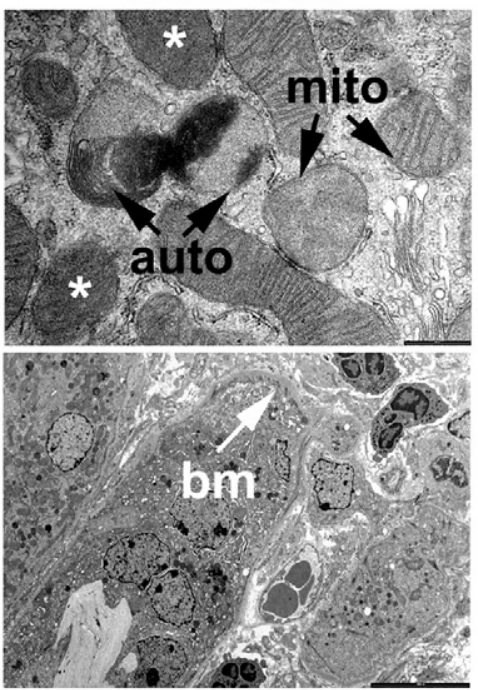

D
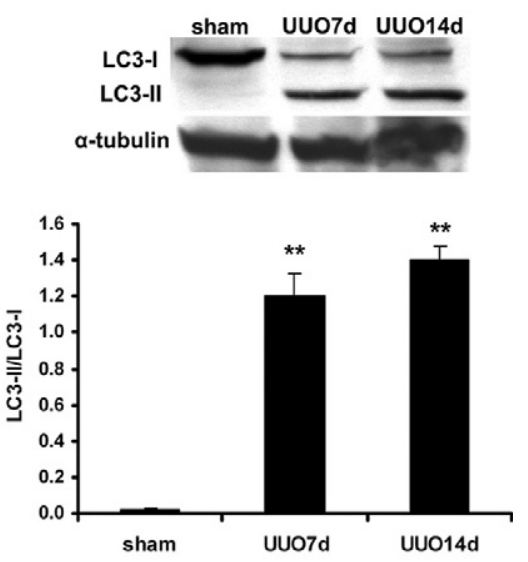

Figure 7. Increased autophagy in the kidneys with UUO. A: Increased formation of autophagic vacuoles and tubular atrophy after UUO. Transmission electron microscopy images show normal structures of the nucleus, mitochondria, and other cellular organelles in the control kidney, and the presence of double membrane vacuoles containing electron dense material and compressed mitochondria with the loss of visible cristae 7 and 14 days after UUO (top panel). Inset shows higher magnification of an autophagosome. Mitochondria with nonautophagy-related internal structural alterations, such as heterogeneously distributed internal cristae and matrix, are indicated by the asterisks. The bottom panel shows normal tubules in control kidneys, and atrophic tubules in the kidneys after 7 and 14 days UUO. mito, mitochondria; auto, autophagic vacuoles; bm, tubular basement membrane. Scale bars: $500 \mathrm{~nm}$ (top panel); 5000 nm (left image on the bottom panel); and 10,000 nm (middle and right images on the bottom panel). B and C: Increased expression of Beclin $1 \mathrm{mRNA}$ detected by real time RT-PCR analysis (B) and Beclin 1 protein detected by immunoblot analysis (C) after UUO. In the representative real time RT-PCR tracing, green curves represent sham, blue curves represent 7 days and red curves represent 14 days after UUO. The mRNA levels are quantified after normalization with $18 \mathrm{~S}$ rRNA and the protein levels are quantified after normalization with $\alpha$-tubulin protein. D: Increased conversion of LC3-I to LC3-II proteins. Values represent mean \pm SE. $n=3$ for each experimental group. ${ }^{*} P<0.05$, and ${ }^{* *} P<0.001$ compared with sham-operated control group.

Immunostaining of control kidney sections showed abundant LAMP-1 in a small punctate pattern in proximal tubules, which contain a large number of lysosomes. No changes in LAMP-1 staining were detected in proximal tubules 3 days after UUO. However, the pattern of LAMP-1 staining became more coarse and granular 7 and 14 days after UUO (Figure 8A). Levels of LAMP-1 protein increased significantly 7 and 14 days after UUO (Figure 8B). Furthermore, levels of lysosomal enzyme cathepsin D protein increased 7 and 14 days after obstruction (Figure 8C). Taken together, these results indicate that accumulation of autophagosomes is not due to diminished lysosomal function but rather reflects increased autophagy in kidneys with obstructive injury.

\section{Autophagy Accompanies Tubular Atrophy and Tubular Cell Death}

To determine whether autophagy is associated with the morphological changes that occur after obstructive injury, we performed periodic acid-Schiff staining to semiquantitatively measure tubular atrophy. In sham-operated kidneys, rare tubular atrophy was observed. Mild to moderate tubular atrophy was detected in the proximal tubules 3 and 7 days after UUO. Prolonged obstruction for 10 and 14 days led to extensive tubular atrophy. At 14 days, about two-thirds of the proximal tubules were atrophic. Terminal deoxynucleotidyl transferase dUTP nick- 
A
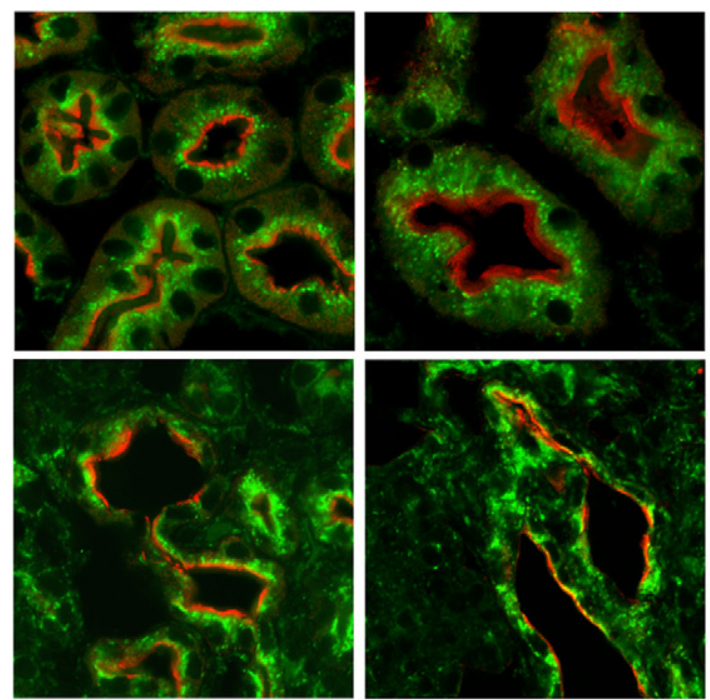

B
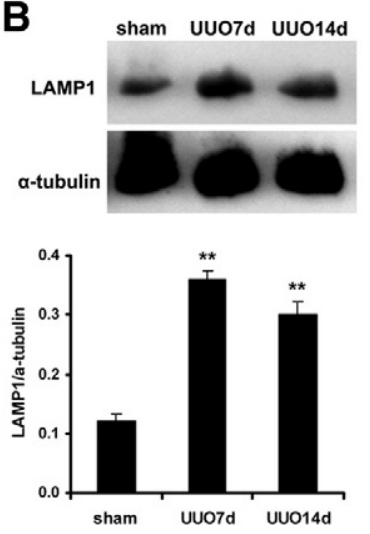

C
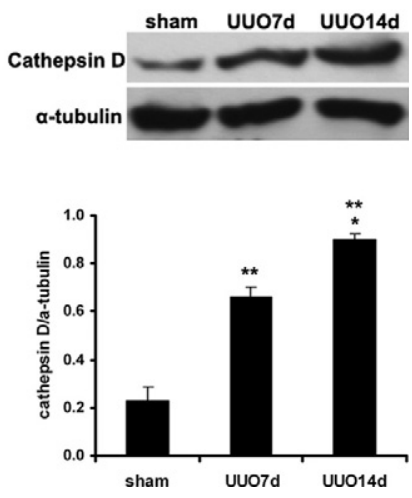

Figure 8. Expression of lysosomal membrane protein LAMP-1 and lysosomal enzyme cathepsin D. A: Co-immunostaining of LAMP-1 (green) and proximal tubular marker LTA (red) indicates abundant LAMP-1 signals in a small punctate pattern in proximal tubules in controls (left upper image) and 3 days post UUO (right upper image). LAMP-1 signals become enhanced and are in a coarse and granular pattern 7 days (left lower image) and 14 days (right lower image) post UUO. B: Immunoblot analysis indicates increased LAMP-1 protein levels post UUO. C: Immunoblot analysis indicates increased cathepsin D protein levels post UUO. Values represent mean \pm SE. $n=3$ for each experimental group. ${ }^{* * *} P<0.001$ between sham and 7 days or 14 days post UUO

end labeling assays showed increased apoptotic cell death following UUO. The percentage of apoptotic cells in the obstructed proximal tubules increased from $2.9 \%$ to $7.6 \%$ at 3 to 14 days after UUO (Table 1). These results indicate the coexistence of autophagy with tubular atrophy and apoptotic cell death in obstructed proximal tubules, which suggests that autophagy plays a role in the epithelial changes that occur in response to obstructive injury.

\section{Discussion}

To trace the fate of renal tubular epithelial cells following urinary tract obstruction, we used transgenic mice that express EYFP exclusively in renal tubular epithelial cells and their progeny cells. Genetic crosses between Cre ${ }^{K s p}$ mice and R26R-EYFP reporter mice resulted in labeling of $21 \%$ of the epithelial cells in proximal tubules and $92 \%$ to
Table 1. Proximal Tubular Atrophy and Apoptosis

\begin{tabular}{lrc}
\hline \multicolumn{1}{c}{ Group } & $\begin{array}{c}\text { \% Atrophic } \\
\text { tubules }\end{array}$ & $\begin{array}{c}\text { \% Apoptotic } \\
\text { cells }\end{array}$ \\
\hline Sham & $0.17 \pm 0.10$ & $0.30 \pm 0.09$ \\
UUO 3 days & $3.54 \pm 0.56$ & $2.92 \pm 0.08$ \\
UUO 7 days & $18.94 \pm 1.39$ & $6.10 \pm 0.01$ \\
UUO 10 days & $32.57 \pm 3.14$ & $7.63 \pm 0.01$ \\
UUO 14 days & $64.15 \pm 4.38$ & $4.29 \pm 0.01$ \\
\hline
\end{tabular}

To examine atrophic changes, PAS staining was performed in the kidney paraffin sections and the proximal tubules were identified by the presence of brush border. A minimum of 1000 tubules were examined for atrophic changes in each sample. To examine apoptosis, TUNEL staining was performed and proximal tubules were labeled with LTA. A total of 10 fields in the cortex were randomly photographed under $\times 400$ magnification in each sample. The apoptotic cells in the proximal tubules were counted. The values represent mean \pm SE. $n=3$.

$100 \%$ of epithelial cells in the distal nephron and collecting ducts. Although the EYFP reporter gene is only activated in renal tubular epithelial cells that express Cre recombinase, once active its continued expression is under the control of the ubiquitous Rosa26 promoter. Therefore, EYFP will be expressed in the labeled tubular cells as well as all their progeny cells, even if the cells migrate out of the tubules or differentiate into other cell types, such as fibroblasts. Using this approach, we traced the fate of the labeled cells in mice that were subjected to UUO to specifically investigate the role of EMT in nephron loss and interstitial fibrosis.

We provide two lines of evidence indicating that tubular epithelial cells do not become myofibroblasts following UUO. First, none of the EYFP-positive cells co-express $\alpha$-SMA, a myofibroblast-specific marker, during the course of renal fibrosis. $\alpha$-SMA is only expressed in EYFP-negative cells within the interstitial compartment. Second, all EYFP-positive cells are confined within the tubular basement membrane and show no expression of another fibroblast marker, S100A4 (FSP1). ${ }^{10,30}$ In our studies using Cre ${ }^{k s} ;$; R6R-EYFP mice, the EYFP reporter gene is only activated in mature renal epithelial cells. We cannot exclude the possibility that myofibroblasts might originate from rare undifferentiated renal stem cells that reside in the tubules but are not labeled with EYFP. However, our studies do not support a substantial contribution of EMT to nephron loss and interstitial fibrosis.

EMT refers to molecular reprogramming and phenotypic changes that occur during the conversion of epithelial cells to mesenchymal cells. EMT occurs under a wide variety of physiological and pathological conditions. It is an essential developmental process and is involved in tumor invasion and metastasis. ${ }^{46}$ During the embryonic development of the kidney, mesenchymal cells differentiate into epithelial cells and form nephrons, reflecting mesenchymal-to-epithelial transition. Prolonged treatment of human proximal tubular epithelial cells with transforming growth factor- $\beta 1$ leads to EMT, ${ }^{47}$ which is the reverse of the process of nephron formation. Since transforming growth factor $\beta 1$ is up-regulated in injured kidneys, such as kidneys with ureteral obstruction, ${ }^{48}$ it is plausible that tubular epithelial cells that originated from the metanephric mesenchyme may be converted to mesenchymal cells in response to certain environmental sig- 
nals. In a landmark study using bitransgenic $R 26 R \times \gamma G T$. Cre mice in which proximal tubular cells are genetically labeled with LacZ, LacZ- and FSP1-co-expressing cells are identified in the kidneys with UUO. Up to $36 \%$ of $\mathrm{FSP}^{+}{ }^{+}$interstitial cells are shown to be derived from LacZ $^{+}$proximal tubular cells 10 days postobstruction, ${ }^{10}$ suggesting that proximal tubular cells are a significant source for interstitial fibroblasts. We did not detect expression of S100A4 in any EYFP-positive cells. Instead, we detected abundant $\mathrm{S} 100 \mathrm{~A} 4^{+}$cells co-expressing leukocyte marker CD45, indicating inflammatory cell infiltration after urinary tract obstruction. The use of antibodies (anti-FSP1 vs. anti-S100A4) from two different sources could account for the discrepancy.

In Cre ${ }^{k s p} ; R 26 R-E Y F P$ mice, $100 \%$ of collecting ducts express EYFP. The absence of expression of $\alpha$-SMA in EYFP-positive cells suggests that epithelial cells in the collecting ducts do not have the ability to form myofibroblasts following UUO. This result could reflect the fact that collecting ducts are derived from the ureteric bud and may not have the ability to cross the lineage boundary to become mesenchymal cells in vivo. The near complete labeling of cells in the thick ascending limbs, distal convoluted tubules, connecting tubules, and collecting ducts argues against EMT in these nephron segments. However, EYFP is only expressed in $21 \%$ of proximal tubular cells, and it is possible that we underestimated EMT in this nephron segment. To specifically address whether proximal tubular cells can revert to a mesenchymal phenotype after obstructive injury, we administered a low molecular weight dextran that is preferentially taken up by proximal tubular cells and tracked the cells after UUO. We labeled $89 \%$ to $98 \%$ of the proximal tubules of wild-type mice with a low molecular weight dextran and did not detect dextran-retaining cells in the interstitium or expressing $\alpha$-SMA. These findings support our conclusion that tubular epithelial cells do not contribute substantially to the formation of interstitial myofibroblasts in vivo. Our results are consistent with recent studies by Lin et $\mathrm{al}^{49}$ who also found no evidence of EMT contributing to interstitial myofibroblasts after UUO or renal ischemic injury. Using mice expressing Cre under the control of the Six2 promotor to genetically label $94 \%$ to $95 \%$ of the epithelial cells of the nephron with red fluorescent protein or LacZ, ${ }^{50}$ they found that labeled epithelial cells did not migrate outside the tubular basement membrane or express $\alpha$-SMA or S100A4 following UUO or ischemic injury.

To investigate alternative mechanisms of nephron loss, we measured autophagy in the postobstructive kidney. We provide the first evidence that autophagy is increased after urinary tract obstruction. The increased autophagy is reflected by an increased number of autophagosomes, increased expression of autophagy-related protein Beclin 1, and increased conversion of LC3-I to LC3-II. The accumulation of autophagosomes is not due to lysosomal dysfunction. Furthermore, autophagy is temporally associated with tubular atrophy. Although autophagy has been identified as a form of nonapoptotic cell death, compelling evidence indicates that the primary role of autophagy is cytoprotection. ${ }^{51}$ Under steady-state con- ditions, autophagy mediates the degradation and recycling of cytoplasmic contents, such as long-lived proteins and organelles. Recent studies in rat kidneys and renal epithelial cells isolated from human nephrectomy specimens suggest that autophagy protects renal tubular cells against cyclosporin toxicity. ${ }^{52}$ Autophagy may prevent apoptosis by selectively removing damaged mitochondria that might otherwise accumulate under stress conditions and release pro-apoptotic factors, such as cytochrome c.

Tubular epithelial cells are metabolically active, rich in mitochondria and have high nutrient requirements. The hypoxic insult that occurs during urinary tract obstruction $^{26}$ may initiate autophagy. The observation that autophagy is accompanied by tubular atrophy suggests that obstructive injury may exceed the capability for self protection through autophagy. It is not clear whether increased autophagy reflects a failure of cytoprotection after extreme injury or if cell death is actually executed by autophagy. Autophagy has a prosurvival function, and suppression of autophagy by knockout or knockdown of essential autophagy genes leads to increased cell death in various types of cells. ${ }^{51,53-55}$ Converesely, cell death mediated by autophagy has been described in the developing Drosophila salivary gland and in Dictyostelium. ${ }^{56,57}$

Autophagy may cooperate with the apoptotic machinery by acting upstream of apoptosis, converging with the apoptotic pathway, or mediating steps downstream of apoptosis. ${ }^{53}$ In fact, Beclin1, which is crucial in autophagosome initiation, was initially identified as a Bcl-2-interacting protein. ${ }^{58}$ Aside from its role in autophagy, Beclin 1 has been shown to participate in the vacuolar protein sorting (Vps) pathway in yeast. ${ }^{59}$ In other species, the involvement of Beclin 1 in nonautophagic pathways remains controversial. ${ }^{60,61}$ The increased level of Beclin 1 protein observed 7 days but not 14 days following UUO suggests that Beclin 1 is not persistently elevated in the obstructed kidney. This finding could suggest that a high level of Beclin 1 is not required once autophagy has been initiated or that Beclin 1 has other unidentified functions in the obstructed kidney. The likelihood of a more complicated role of Beclin 1 is supported by studies showing no change in Beclin 1 protein abundance in mouse cardiomyocytes when autophagy is induced by short-term starvation. In contrast, when a similar degree of autophagy is induced by pressure overload to the heart, Beclin 1 levels change significantly. ${ }^{45}$

Presently, there is no direct evidence that autophagy by itself induces cell death in mammalian cells in vivo. Increased death of cardiomyocytes in response to ischemia-reperfusion injury or pressure overload is associated with increases in autophagy, apoptosis and necrosis. ${ }^{45,62}$ Similar to the cardiomyocytes, autophagy in the kidney could represent the failure of renal tubular epithelial cells to repair or a mechanism of cell death resulting from excessive self-cannibalism following obstructive injury. Future studies modulating autophagy with chemical or molecular reagents and using beclin deficient mice could provide further answers to the role of autophagy in the obstructed kidney. 
In summary, we investigated epithelial cell fate in adult mouse kidneys following complete ureteral obstruction and found no evidence of EMT. We conclude that EMT does not contribute substantially to interstitial myofibroblast formation. Furthermore, we demonstrate that autophagy occurs in the epithelial cells with obstructive uropathy. Further understanding of the mechanism of tubular epithelial injury and survival will facilitate the development of therapeutic strategies to prevent end-stage renal disease resulting from obstructive uropathy.

\section{Acknowledgments}

We thank Dr. Peter Igarashi, Dr. Beth Levine, and Dr. Joseph Zhou for helpful discussions, Samuel Bradshaw for excellent technical assistance, and Courtney Karner for critical reading of the manuscript. We thank Dr. Chris Gilpin and Tom Januszewski (Electron Microscopy Core, UT Southwestern Medical Center) and Dr. Arthur Weinberg (Children's Medical Center of Dallas) for helping with transmission electron microscopy studies.

\section{References}

1. Smith JM, Stablein DM, Munoz R, Hebert D, McDonald RA: Contributions of the transplant registry: the 2006 annual report of the North American Pediatric Renal Trials and Collaborative Studies (NAPRTCS). Pediatr Transplant 2007, 11:366-373

2. Chevalier RL: Pathogenesis of renal injury in obstructive uropathy. Curr Opin Pediatr 2006, 18:153-160

3. Chevalier RL, Peters CA: Congenital urinary tract obstruction: proceedings of the State-Of-The-Art Strategic Planning Workshop-National Institutes of Health. Bethesda, Maryland, 11-12 March 2002. Pediatr Nephrol 2003, 18:576-606

4. Woolf AS, Price KL, Scambler PJ, Winyard PJ: Evolving concepts in human renal dysplasia. J Am Soc Nephrol 2004, 15:998-1007

5. Potter E: Normal and abnormal development of the kidney. Edited by Chicago, Year Book Medical Publishers, 1972, pp. 1-305

6. Bascands JL, Schanstra JP: Obstructive nephropathy: insights from genetically engineered animals. Kidney Int 2005, 68:925-937

7. Gobe GC, Axelsen RA: Genesis of renal tubular atrophy in experimental hydronephrosis in the rat. Role of apoptosis, Lab Invest 1987, 56:273-281

8. Kalluri R, Neilson EG: Epithelial-mesenchymal transition and its implications for fibrosis. J Clin Invest 2003, 112:1776-1784

9. Liu Y: Epithelial to mesenchymal transition in renal fibrogenesis: pathologic significance, molecular mechanism, and therapeutic intervention. J Am Soc Nephrol 2004, 15:1-12

10. Iwano M, Plieth D, Danoff TM, Xue C, Okada H, Neilson EG: Evidence that fibroblasts derive from epithelium during tissue fibrosis. J Clin Invest 2002, 110:341-350

11. Faulkner JL, Szcykalski LM, Springer F, Barnes JL: Origin of interstitial fibroblasts in an accelerated model of angiotensin II-induced renal fibrosis. Am J Pathol 2005, 167:1193-1205

12. Le Hir M, Hegyi I, Cueni-Loffing D, Loffing J, Kaissling B: Characterization of renal interstitial fibroblast-specific protein 1/S100A4-positive cells in healthy and inflamed rodent kidneys. Histochem Cell Biol 2005, 123:335-346

13. Klionsky DJ: Autophagy: from phenomenology to molecular understanding in less than a decade. Nat Rev Mol Cell Biol 2007, 8:931-937

14. Levine B, Kroemer G: Autophagy in the pathogenesis of disease. Cell 2008, 132:27-42

15. Levine B, Sinha S, Kroemer G: Bcl-2 family members: dual regulators of apoptosis and autophagy. Autophagy 2008, 4:600-606

16. Shao X, Johnson JE, Richardson JA, Hiesberger T, Igarashi P: A minimal Ksp-cadherin promoter linked to a green fluorescent pro- tein reporter gene exhibits tissue-specific expression in the developing kidney and genitourinary tract. J Am Soc Nephrol 2002, 13:1824-1836

17. Shao X, Somlo S, Igarashi P: Epithelial-specific Cre/lox recombination in the developing kidney and genitourinary tract. J Am Soc Nephrol 2002, 13:1837-1846

18. Srinivas S, Watanabe T, Lin CS, William CM, Tanabe Y, Jessell TM, Costantini $F$ : Cre reporter strains produced by targeted insertion of EYFP and ECFP into the ROSA26 locus. BMC Dev Biol 2001, 1:1-8

19. Li L, Truong P, Igarashi P, Lin F: Renal and bone marrow cells fuse after renal ischemic injury. J Am Soc Nephrol 2007, 18:3067-3077

20. Nadasdy T, Laszik Z, Blick KE, Johnson DL, Silva FG: Tubular atrophy in the end-stage kidney: a lectin and immunohistochemical study. Hum Pathol 1994, 25:22-28

21. Zhou XJ, Laszik Z, Wang XQ, Silva FG, Vaziri ND: Association of renal injury with increased oxygen free radical activity and altered nitric oxide metabolism in chronic experimental hemosiderosis. Lab Invest 2000, 80:1905-1914

22. Hiesberger T, Bai Y, Shao X, McNally BT, Sinclair AM, Tian X, Somlo S, Igarashi P: Mutation of hepatocyte nuclear factor-1beta inhibits Pkhd1 gene expression and produces renal cysts in mice. J Clin Invest 2004, 113:814-825

23. Pfaffl MW: A new mathematical model for relative quantification in real-time RT-PCR. Nucleic Acids Res 2001, 29:e45

24. Yu W, Sandoval RM, Molitoris BA: Quantitative intravital microscopy using a Generalized Polarity concept for kidney studies. Am J Physiol Cell Physiol 2005, 289:C1197-C1208

25. Cochrane AL, Kett MM, Samuel CS, Campanale NV, Anderson WP Hume DA, Little MH, Bertram JF, Ricardo SD: Renal structural and functional repair in a mouse model of reversal of ureteral obstruction. J Am Soc Nephrol 2005, 16:3623-3630

26. Cachat F, Lange-Sperandio B, Chang AY, Kiley SC, Thornhill BA Forbes MS, Chevalier RL: Ureteral obstruction in neonatal mice elicits segment-specific tubular cell responses leading to nephron loss. Kidney Int 2003, 63:564-575

27. Docherty NG, O'Sullivan OE, Healy DA, Fitzpatrick JM, Watson RW Evidence that inhibition of tubular cell apoptosis protects against renal damage and development of fibrosis following ureteric obstruction. Am J Physiol Renal Physiol 2006, 290:F4-F13

28. Igarashi $P$, Shao X, McNally BT, Hiesberger T: Roles of HNF-1beta in kidney development and congenital cystic diseases. Kidney Int 2005 , 68:1944-1947

29. Ott MO, Rey-Campos J, Cereghini S, Yaniv M: VHNF1 is expressed in epithelial cells of distinct embryonic origin during development and precedes HNF1 expression. Mech Dev 1991, 36:47-58

30. Strutz F, Okada H, Lo CW, Danoff T, Carone RL, Tomaszewski JE, Neilson EG: Identification and characterization of a fibroblast marker: fSP1. J Cell Biol 1995, 130:393-405

31. Barraclough R: Calcium-binding protein S100A4 in health and disease. Biochim Biophys Acta 1998, 1448:190-199

32. Mazzucchelli L: Protein S100A4: too long overlooked by pathologists? Am J Pathol 2002, 160:7-13

33. Taylor S, Herrington S, Prime W, Rudland PS, Barraclough R: S100A4 (p9Ka) protein in colon carcinoma and liver metastases: association with carcinoma cells and T-lymphocytes. $\mathrm{Br} J$ Cancer 2002, 86: 409-416

34. Gustafsson AB, Gottlieb RA: Recycle or die: the role of autophagy in cardioprotection. J Mol Cell Cardiol 2008, 44:654-661

35. Arendshorst WJ, Finn WF, Gottschalk CW: Nephron stop-flow pressure response to obstruction for 24 hours in the rat kidney. $\mathrm{J}$ Clin Invest 1974, 53:1497-1500

36. Huland $\mathrm{H}$, Leichtweiss HP, Augustin HJ: Effect of angiotensin II antagonist, alpha-receptor blockage, and denervation on blood flow reduction in experimental, chronic hydronephrosis. Invest Urol 1980, 18:203-206

37. Rao NR, Heptinstall RH: Experimental hydronephrosis. A microangiographic study. Invest Urol 1968, 6:183-204

38. Klionsky DJ, Abeliovich $\mathrm{H}$, Agostinis P, Agrawal DK, Aliev G, Askew DS, Baba M, Baehrecke EH, Bahr BA, et al. Guidelines for the use and interpretation of assays for monitoring autophagy in higher eukaryotes. Autophagy 2008, 4:151-175

39. Kihara A, Kabeya Y, Ohsumi Y, Yoshimori T: Beclin-phosphatidylinositol 3-kinase complex functions at the trans-Golgi network. EMBO Rep 2001, 2:330-335 
40. Suzuki K, Kirisako T, Kamada Y, Mizushima N, Noda T, Ohsumi Y: The pre-autophagosomal structure organized by concerted functions of APG genes is essential for autophagosome formation. EMBO J 2001, 20:5971-5981

41. Axe EL, Walker SA, Manifava M, Chandra P, Roderick HL, Habermann A, Griffiths G, Ktistakis NT: Autophagosome formation from membrane compartments enriched in phosphatidylinositol 3-phosphate and dynamically connected to the endoplasmic reticulum. J Cell Biol 2008, 182:685-701

42. Walker S, Chandra P, Manifava M, Axe E, Ktistakis NT: Making autophagosomes: localized synthesis of phosphatidylinositol 3-phosphate holds the clue. Autophagy 2008, 4:1093-1096

43. Yue Z, Jin S, Yang C, Levine AJ, Heintz N: Beclin 1, an autophagy gene essential for early embryonic development, is a haploinsufficient tumor suppressor. Proc Natl Acad Sci USA 2003, 100: 15077-15082

44. Qu X, Yu J, Bhagat G, Furuya N, Hibshoosh H, Troxel A, Rosen J, Eskelinen EL, Mizushima N, Ohsumi Y, Cattoretti G, Levine B: Promotion of tumorigenesis by heterozygous disruption of the beclin 1 autophagy gene. J Clin Invest 2003, 112:1809-1820

45. Zhu H, Tannous P, Johnstone JL, Kong Y, Shelton JM, Richardson JA, Le V, Levine B, Rothermel BA, Hill JA: Cardiac autophagy is a maladaptive response to hemodynamic stress. J Clin Invest 2007, 117:1782-1793

46. Thiery JP, Sleeman JP: Complex networks orchestrate epithelialmesenchymal transitions. Nat Rev Mol Cell Biol 2006, 7:131-142

47. Yang J, Liu Y: Dissection of key events in tubular epithelial to myofibroblast transition and its implications in renal interstitial fibrosis. Am J Pathol 2001, 159:1465-1475

48. Sato M, Muragaki Y, Saika S, Roberts AB, Ooshima A: Targeted disruption of TGF-beta1/Smad3 signaling protects against renal tubulointerstitial fibrosis induced by unilateral ureteral obstruction. J Clin Invest 2003, 112:1486-1494

49. Lin SL, Humphreys BD, Nowlin B, Bonventre JV, Vlaerius T, McMahon AP, Duffield JS: Evidence that epithelial to mesenchymal transition does not result in the generation of myofibroblasts in the kidney. J Am Soc Nephrol, Renal Week Abstract Archives 2008, 19:32A, Abstract TH-FC145

50. Humphreys BD, Valerius MT, Kobayashi A, Mugford JW, Soeung S,
Duffield JS, McMahon AP, Bonventre JV: Intrinsic epithelial cells repair the kidney after injury. Cell Stem Cell 2008, 2:284-291

51. Levine B, Kroemer G: Autophagy in aging, disease and death: the true identity of a cell death impostor. Cell Death Differ 2009, 16:1-2

52. Pallet N, Bouvier N, Legendre C, Gilleron J, Codogno P, Beaune P Thervet E, Anglicheau D: Autophagy protects renal tubular cells against cyclosporine toxicity. Autophagy 2008, 4:783-791

53. Scarlatti F, Granata R, Meijer AJ, Codogno P: Does autophagy have a license to kill mammalian cells? Cell Death Differ 2009, 16:12-20

54 . Kourtis N, Tavernarakis N: Autophagy and cell death in model organisms. Cell Death Differ 2009, 16:21-30

55. Maiuri MC, Zalckvar E, Kimchi A, Kroemer G: Self-eating and selfkilling: crosstalk between autophagy and apoptosis. Nat Rev Mol Cell Biol 2007, 8:741-752

56. Berry DL, Baehrecke EH: Growth arrest and autophagy are required for salivary gland cell degradation in Drosophila. Cell 2007, 131: $1137-1148$

57. Lam D, Kosta A, Luciani MF, Golstein P: The inositol 1,4,5-trisphosphate receptor is required to signal autophagic cell death. Mol Biol Cell 2008, 19:691-700

58. Liang XH, Kleeman LK, Jiang HH, Gordon G, Goldman JE, Berry G, Herman B, Levine B: Protection against fatal Sindbis virus encephalitis by beclin, a novel Bcl-2-interacting protein. J Virol 1998, 72: 8586-8596

59. Kihara A, Noda T, Ishihara N, Ohsumi Y: Two distinct Vps34 phosphatidylinositol 3-kinase complexes function in autophagy and carboxypeptidase $Y$ sorting in Saccharomyces cerevisiae. J Cell Biol 2001, 152:519-530

60. Takacs-Vellai K, Vellai T, Puoti A, Passannante M, Wicky C, Streit A Kovacs AL, Muller F: Inactivation of the autophagy gene bec-1 triggers apoptotic cell death in C. elegans. Curr Biol 2005, 15:1513-1517

61. Zeng $\mathrm{X}$, Overmeyer $\mathrm{JH}$, Maltese WA: Functional specificity of the mammalian Beclin-Vps34 PI 3-kinase complex in macroautophagy versus endocytosis and lysosomal enzyme trafficking. J Cell Sci 2006, 119:259-270

62. Hamacher-Brady A, Brady NR, Logue SE, Sayen MR, Jinno M, Kirshenbaum LA, Gottlieb RA, Gustafsson AB: Response to myocardial ischemia/reperfusion injury involves Bnip3 and autophagy. Cell Death Differ 2007, 14:146-157 